\title{
Presynaptic Fmrl Genotype Influences the Degree of Synaptic Connectivity in a Mosaic Mouse Model of Fragile X Syndrome
}

\author{
Jesse E. Hanson and Daniel V. Madison \\ Department of Molecular and Cellular Physiology, Stanford University School of Medicine, Stanford, California 94305
}

\begin{abstract}
Almost all female and some male fragile X syndrome (FXS) patients are mosaic for expression of the FMR1 gene, yet all research in models of FXS has been in animals uniformly lacking Fmrl expression. Therefore, we developed a system allowing neuronal genotype to be visualized in vitro in mouse brain slices mosaic for Fmr1 expression. Whole-cell recordings from individual pairs of presynaptic and postsynaptic neurons in organotypic hippocampal slices were used to probe the cell-autonomous effects of Fmr1 genotype in mosaic networks. These recordings revealed that wild-type presynaptic neurons formed synaptic connections at a greater rate than presynaptic neurons lacking normal Fmrl function in mosaic networks. At the same time, the postsynaptic Fmrl genotype did not influence the probability that a neuron received synaptic connections. Asymmetric presynaptic function during development of the brain could result in a decreased participation in network function by the portion of neurons lacking FMR1 expression.
\end{abstract}

Key words: Fmr1; FMRP; mosaic; whole cell; fragile X syndrome; autism; CA3; connectivity; hippocampus; presynaptic

\section{Introduction}

Fragile X syndrome (FXS) is one of the most common inherited forms of mental retardation (Crawford et al., 2001). FXS is caused by trinucleotide expansion within the FMR1 gene on the X chromosome resulting in hypermethylation of the $5^{\prime}$ untranslated region and loss of fragile $\mathrm{X}$ mental retardation protein (FMRP) expression (Pieretti et al., 1991). FXS patients suffer mental retardation, macroorchidism, facial dysmorphologies, and behavioral problems (Hagerman, 2002) as well as a high incidence of epilepsy (Musumeci et al., 1999). Because a small but significant proportion of children with autism spectrum disorder (ASD) have a mutation in the FMR1 gene (Brown et al., 1986) and up to $33 \%$ of children with FXS fulfill a diagnosis of autism (Rogers et al., 2001), FXS is considered to be a genetic model of ASD (Hagerman et al., 2005).

Male patients carry the mutation on their single X chromosome and typically exhibit relatively severe mental impairment whereas female patients heterozygous for the mutation are generally less severely impaired (Reiss et al., 1995). In female patients, X-inactivation silences either the mutant or normal X chromosome in each cell, resulting in mosaic FMRP expression, with variable skewing of $\mathrm{X}$ inactivation leading to variability in the percentage of cells expressing FMRP (Martínez et al., 2005). In addition, variable silencing of the FMR1 gene in different cells,

\footnotetext{
Received 0ct. 30, 2006; revised Feb. 21, 2007; accepted March 6, 2007.

This work was supported by National Institutes of Health Grants MH65541 (D.V.M.) and NS047849 (J.E.H.). We thank Johanna Montgomery for helpful input during the preparation of this manuscript.

Correspondence should be addressed to Daniel V. Madison, Department of Molecular and Cellular Physiology, Stanford University School of Medicine, 003 Beckman Center, Stanford School of Medicine, Stanford, CA 94305. E-mail:madison@stanford.edu.

DOI:10.1523/JNEUROSCI.4717-06.2007

Copyright $\odot 2007$ Society for Neuroscience $\quad$ 0270-6474/07/274014-05\$15.00/0
}

can results in mosaic expression of FMRP in some male patients (Pieretti et al., 1991; Nolin et al., 1994; Rousseau et al., 1994).

The mouse model of FXS is a knock-out (KO) of the Fmr1 gene and exhibits many phenotypic characteristics of FXS (The Dutch-Belgian Fragile X Consortium, 1994). This model has proven to be of great value in probing the alterations that result from loss of Fmr1 gene function (Kooy, 2003). For example, electrophysiological recordings have demonstrated both reduced long-term synaptic potentiation in the cortex and amygdala (Li et al., 2002; Larson et al., 2005; Zhao et al., 2005) and enhanced long-term synaptic depression in the hippocampus and cerebellum of Fmrl KO mice (Huber et al., 2002; Koekkoek et al., 2005). Although the insight gained from such work has provided hope for identifying therapeutic targets (Bear et al., 2004), no studies have addressed the neuropathology specific to mosaic brains that contain neurons both with and without active Fmrl. Therefore, to gain insight into the types of neuronal alterations that could exist in FXS patients with mosaic FMR1 expression, we developed a system that models mosaic FXS, and is amenable to electrophysiological recordings from neurons of known genotype. Measurements of individual synaptic connections using this approach revealed a novel cell-autonomous presynaptic role for Fmrl function in the establishment of functional synaptic connections.

\section{Materials and Methods}

Animals. All experiments were performed using F1 females from the breeding of Fmr1 KO or Fmrl wild-type (WT) controls on an FVB background (FVB.129P2-Fmr1 ${ }^{\mathrm{tm} 1 \mathrm{Cgr}} / \mathrm{J}$, JAX catalog \#4624, or FVB.129P2-Pde6b ${ }^{+} \mathrm{Tyr}^{\text {c-ch }} /$ AntJ, JAX catalog \#4828; The Jackson Laboratory, Bar Harbor, ME) to mice carrying a green fluorescent protein (GFP) transgene on their X chromosome (Hadjantonakis et al., 1998) that were originally from a mixed 129/ICR background [stock transgenic(GFPX)4Nagy/J, JAX catalog \#3116] and had been 
A
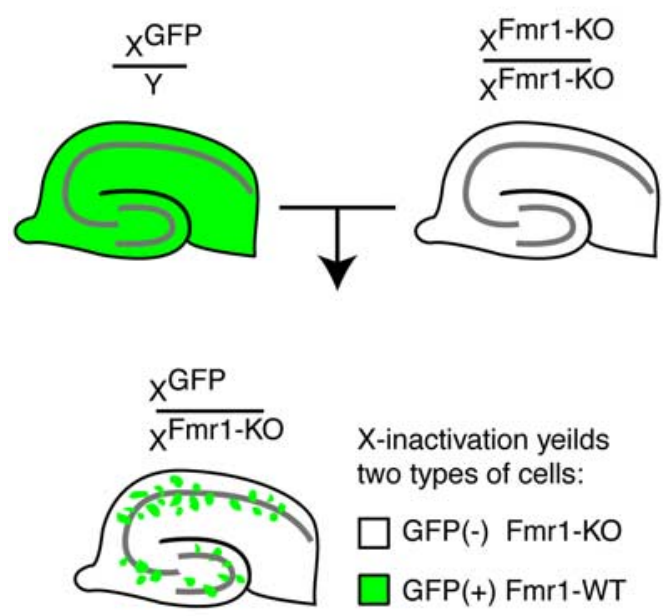

B

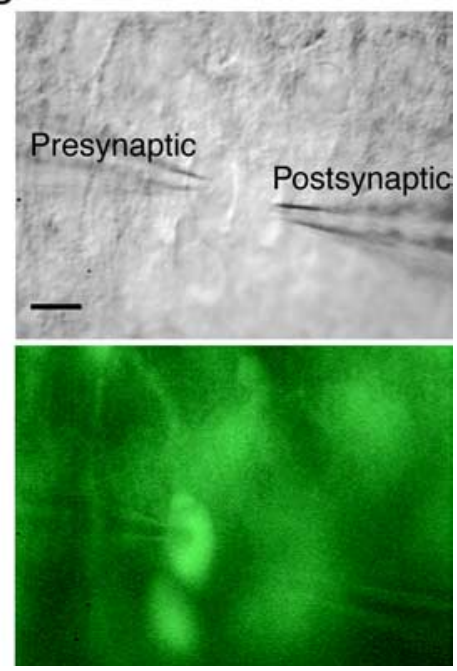

Figure 1. Generation of labeled mosaics for electrophysiological recordings. $\boldsymbol{A}$, Generation of mosaic F1 female mice for generation of hippocampal slices (see Results). $\boldsymbol{B}$, Example IR-DIC and epifluorescence images of recorded presynaptic and postsynaptic neurons. In this example, the presynaptic neuron is GFP(+) and therefore Fmr1 WT, whereas the postsynaptic neuron is GFP (-) and therefore Fmr $1 \mathrm{KO}$. Scale bar, $10 \mu \mathrm{m}$.

backcrossed onto the 129 background for six generations before use in this study.

Organotypic slices. Interface cultures of hippocampal slices were made from 5- to 6 -d-old mice ( $n=9$ Fmrl mosaic; 9 control mosaic). Hippocampi were dissected in minimum essential medium (MEM; Invitrogen, Eugene, OR) with $15 \mathrm{~mm}$ HEPES and $10 \mathrm{~mm}$ Tris buffer (Invitrogen). Four-hundred micrometer slices were cultured on Millicell CM culture plate inserts (Millipore, Temecula, CA). The culture medium consisted of 50\% MEM, 25\% HBSS, and 25\% horse serum, with $12.5 \mathrm{~mm}$ HEPES buffer and penicillin $(100 \mathrm{U} / \mathrm{ml}) /$ streptomycin $(100 \mu \mathrm{g} / \mathrm{ml})$ (all from Invitrogen). Cultures were maintained in $5 \% \mathrm{CO}_{2}$, at $37^{\circ} \mathrm{C}$ for $3 \mathrm{~d}$ and then at $34^{\circ} \mathrm{C}$ for the remaining culture period. Slices were recorded from after 6-10 d in culture.

Neuron visualization. Pyramidal cells in area CA3 were visualized by infrared differential interference contrast microscopy (IR-DIC) and GFP labeling was visualized using epifluorescence. Photobleaching and phototoxicity were minimized by shuttering the UV light source so as to illuminate the slice for a duration of 50-150 ms at 1.5-2 s intervals using a Lambda SC Smart Shutter (Sutter, Novato, CA). Presynaptic recordings were obtained first and then potential postsynaptic partners were targeted so as to allow visualization of both neurons within the same field of view of the microscope. That control GFP mosaics showed no alterations to presynaptic or postsynaptic connectivity (see Fig. $4 b$ ) indicates that these measurements were free of any artifact that could have theoretically been caused by unintentional biasing of the distance between pairs of neurons as a function of GFP expression.

After seal formation, but before going whole-cell, the presence or absence of GFP in each recorded neuron was confirmed as follows: 16-24 frames of epifluorescence were captured from an analog video camera and averaged using a LG-3 frame-grabber (Scion, Frederick, MD) and the contrast and brightness of the average image were optimized ( $\mathrm{Pho-}$ toshop; Adobe, San Jose, CA). The image of the fluorescence was then aligned with an IR-DIC image from the same focal plane showing the position of the recording electrode and the cell body. As confirmation of $\mathrm{GFP}(+)$ status, at the end of each recording we examined another image of the recorded neuron to confirm that the soluble GFP had dialyzed out of the neuron and into the whole-cell electrode. As confirmation of $\mathrm{GFP}(-)$ status, at the end of the experiment the recorded neuron was imaged again to confirm the persistence of the background fluorescence (i.e., no evidence of dialysis of intracellular GFP).

Electrophysiological recordings. One to three independent pairs of neurons were recorded per slice and when multiple pairs were recorded in

the same slice, pairs with differing genotype profiles were targeted. On average, approximately four slices were used from each animal. Slices were immersed in oxygenated artificial CSF at room temperature, containing (in $\mathrm{mm}$ ) $119 \mathrm{NaCl}, 2.5 \mathrm{KCl}, 1.3 \mathrm{MgSO}_{4}, 2.5 \mathrm{CaCl} 2,1$ $\mathrm{Na}_{2} \mathrm{HPO}_{4}, 26.2 \mathrm{NaHCO} 3$, and 11 glucose, perfused at a rate of $2 \mathrm{ml} / \mathrm{min}$. The internal electrode solution consisted of the following (in $\mathrm{mm}$ ): $120 \mathrm{~K}$ gluconate (presynaptic cell) or Cs gluconate (postsynaptic cell), 40 HEPES, 5 MgCl2, 0.3 MgGTP, 2 NaATP, and 5 QX314 [N-(2,6-dimethylphenylcarbamoylmethyl) triethylammonium chloride; postsynaptic cell only], pH 7.2, with $\mathrm{KOH}$ or CsOH. Presynaptic neurons were held in current-clamp mode and postsynaptic neurons were voltage clamped using a MultiClamp 700A amplifier (Molecular Devices, Foster City, CA). Input resistance was measured in postsynaptic neurons and was not significantly different between WT and KO neurons in mosaic slices (mean $\pm \mathrm{SD}, 267 \pm$ $153 \mathrm{M} \Omega$ for WT vs $265 \pm 126$ for $\mathrm{KO} ; n=26$ and 32 , respectively; $p>0.05, t$ test). Presynaptic cells were kept at $-70 \mathrm{mV}$ by injection of bias current and action potentials were induced by $20 \mathrm{~ms}$ current pulses (typically $20 \mathrm{pA}$ ) and were elicited at $0.1 \mathrm{~Hz}$. Action potential threshold measured during the current pulses did not significantly differ between WT and $\mathrm{KO}$ neurons $(-37.8 \pm 3.6 \mathrm{mV}$ for WT vs $-36.5 \pm 4.4$ for $\mathrm{KO} ; p>0.05 t$ test). Postsynaptic currents in response to presynaptic action potential firing were recorded while the postsynaptic cell was held at $-70 \mathrm{mV}$. All neuron pairs not showing a functional connection were tested by pairing $1 \mathrm{~Hz}$ presynaptic with depolarization of the postsynaptic neuron to $0 \mathrm{mV}$. In contrast to work in different mouse strains (Hanson et al., 2007), silent synapses (synapses without initial responses at $-70 \mathrm{mV}$, but which could be awakened by this stimuli) were very infrequently observed ( $~ 5 \%$ occurrence). Because the occurrence was too low, this class of synapse could not be independently analyzed. However, this indicates that strong synaptic activation did not significantly cause new connections to form.

Statistics. The proportions of pairs of neurons that were connected versus unconnected were compared using Pearson's $\chi^{2}$ test to analyze the raw number of observations of each category as a function of genotype.

\section{Results}

To create a tractable model of mosaic expression, homozygous Fmr1 KO mice on a FVB background were bred to mice with a GFP transgene on their X chromosome on a predominantly 129 background (Fig. 1A). The F1 female offspring of this cross have one $\mathrm{X}$ chromosome that is Fmrl $\mathrm{KO}$ and one $\mathrm{X}$ chromosome that is Fmrl WT and carries the GFP transgene. During embryonic development of these $\mathrm{F} 1$ females, the process of $\mathrm{X}$ inactivation leaves each neuron in the brain either Fmrl KO and GFP( $(-)$ or Fmrl WT and GFP(+). Likely because the X chromosome with the GFP transgene is from the 129 strain and therefore carries the weakest X controlling element (Xce) allele, Xce ${ }^{\mathrm{a}}$ (Simmler et al., 1993), skewed X inactivation was observed in the F1 mosaic females, with a minority of cells expressing GFP $(\sim 10 \%)$. Because the pyramidal cells body layer spreads out during flattening of the slices in culture, clumps of GFP $(+)$ neurons that might be expected in vivo because of the clonal organization of the hippocampus were not observed. Instead, a salt and pepper pattern was observed that facilitated visual identification of the GFP $(+)$ neurons, which were distributed among the more abundant GFP(-) neurons (Fig. 1B). The same GFP expression pattern was seen when Fmrl WT controls were bred to the GFP trans- 
genic mice, indicating that the skewing was not related to Fmrl function.

The GFP labeling of wild-type cells allowed us to target whole-cell recordings to CA3 pyramidal neurons of known genotype during measurements from potentially synaptically coupled pairs of neurons in organotypic hippocampal slices (Fig. $1 B)$. The organotypic preparation was chosen because synaptic regrowth after slicing makes feasible the measurement of individual synaptic connections between natural synaptic partners. We did not detect any differences in synaptic efficacy attributable to either presynaptic or postsynaptic Fmrl genotype in synaptically coupled pairs of neurons (Fig. 2), which is consistent with field recordings from hemizygous Fmr1 KO mice showing no abnormalities in stimulus-response relationships or paired-pulse ratios (Godfraind et al., 1996; Huber et al., 2002).

In contrast to analysis of the efficacy of synapses that were encountered during recordings from pairs of neurons, analysis of the probability of encountering a functional synaptic connection revealed a striking presynaptic effect of Fmrl genotype (Fig. 3). Specifically, Fmr1 KO presynaptic neurons were found to make functional synapses onto WT and $\mathrm{KO}$ postsynaptic neurons in only 44 and 39\% of recordings, respectively, whereas Fmr1WT presynaptic neurons made functional synapses onto WT and $\mathrm{KO}$ neurons in 70 and $71 \%$ of recordings, respectively. The converse of these observations is that Fmrl genotype had no relationship to the probability that postsynaptic neurons received functional synapses. To determine the statistical significance of these observations, the raw numbers of recordings showing a connection or no connection were compared as either a function of presynaptic genotype or postsynaptic genotype using the Pearson's $\chi^{2}$ test (Fig. 4A). This anal$y$ sis indicated that although presynaptic genotype had a significant effect on the number of connections formed [17 connected and 7 unconnected (WT) vs 14 and $20(\mathrm{KO})$, respectively; $p=0.026$ ], there was no significant effect caused by postsynaptic genotype [14 and 12 (WT) vs 17 and 15 (KO), respectively; $p=0.956]$.

Thus, it appears that Fmrl KO presynaptic neurons are impaired at establishing or maintaining synapses compared with Fmr1 WT presynaptic neurons, whereas the ability of postsynaptic neurons to receive connections is independent of Fmr1 genotype.

As a control, we repeated the measurements of connection probability in GFP mosaic mice generated from the breeding of GFP transgene carrying mice to Fmrl WT mice from the same genetic background as the Fmr1 KO mice (Fig. 4B). Recordings from these control mosaics revealed no significant differences in respectively; $p>0.05$ ). but not postsynaptic genotype.
B

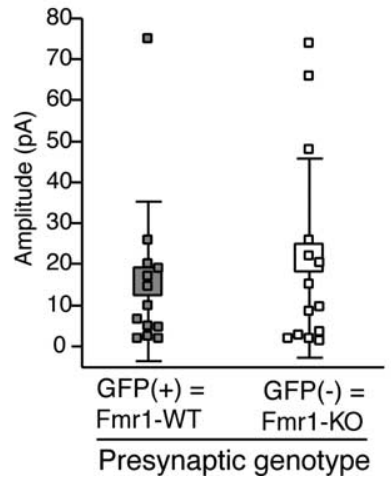

C

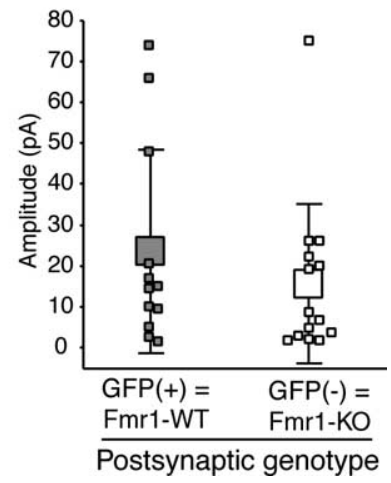

Figure 2. Synaptic amplitudes as a function of presynaptic or postsynaptic genotype. $A$, Example current-clamp recording of an action potential elicited by a brief injection of current in a presynaptic pyramidal neuron (bottom) and the resulting EPSC recorded from a postsynaptic pyramidal neuron voltage clamped at $-70 \mathrm{mV}$ (top). $\boldsymbol{B}$, There was no significant difference in the average amplitudes of EPSC recorded in synaptically connected pairs of neurons based on the presynaptic Fmr 1 genotype (mean \pm SD pA is shown, $15.7 \pm 19.5 \mathrm{Fmr} 1 \mathrm{WT}$ vs $21.5 \pm 24.3 \mathrm{Fmr} 1 \mathrm{KO} ; n=13$ and 14 , respectively; $p>0.05, t$ test). C, There was also no significant difference based on the postsynaptic Fmr1 genotype (23.6 \pm 24.9 Fmr 1 WT vs $14.8 \pm 19.1$ Fmr $1 \mathrm{KO} ; n=12$ and 15 ,

A

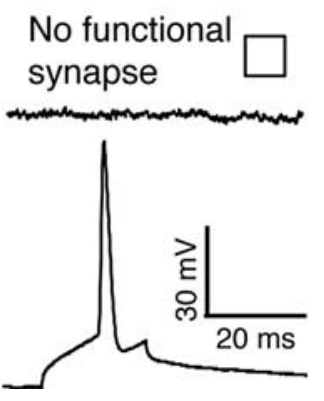

B

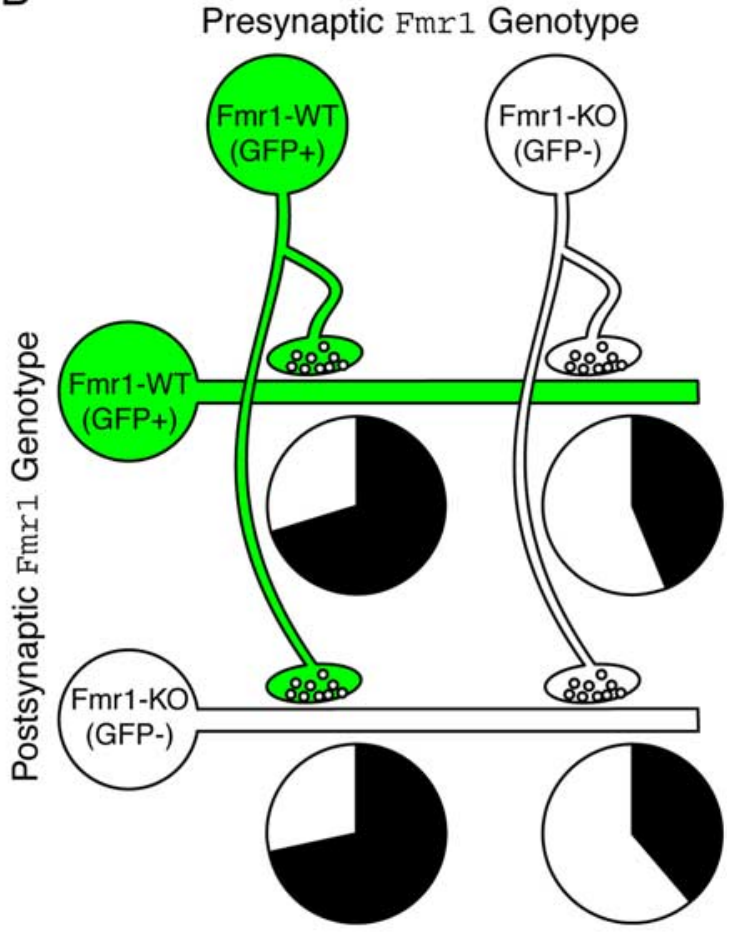

Figure 3. Synaptic connection probability in mosaic slices. $\boldsymbol{A}$, Whereas some pairs of neurons shared functional synaptic connections as defined by the presence of an EPSC at $-70 \mathrm{mV}$, other pairs did not (see Materials and Methods). $\boldsymbol{B}$, Pie charts show the proportions of pairs with functional synapses (black) as a function of both presynaptic and postsynaptic Fmr 1 genotypes $(n=$ $58 ; 10$ WT $\rightarrow$ WT, $16 \mathrm{KO} \rightarrow$ WT, 14 WT $\rightarrow$ KO, 18 KO $\rightarrow$ K0). Note that connection probability varies with presynaptic genotype

the numbers of connections between $\mathrm{GFP}(+)$ or GFP $(-)$ neurons as a function of either presynaptic [10 connected, 14 unconnected (WT) vs 15 and 19 (KO), respectively; $p=0.853$ ], or postsynaptic genotype [11 and 15 (WT) vs 14 and $18(\mathrm{KO}) ; p=$ 0.912 ). These results rule out any potential contributions of the GFP transgene or strain differences in X chromosome genes to the finding of altered presynaptic connectivity.

Comparison of the Fmrl mosaics (Fig. $4 B$ ) to the uniformly Fmr1 WT control mosaics (Fig. $4 B$ ) suggests that the differential 
A
Fmr1 Mosaics

$\square \mathrm{GFP}(+)=$ Fmr1-WT

$\square \mathrm{GFP}(-)=$ Fmr1-KO

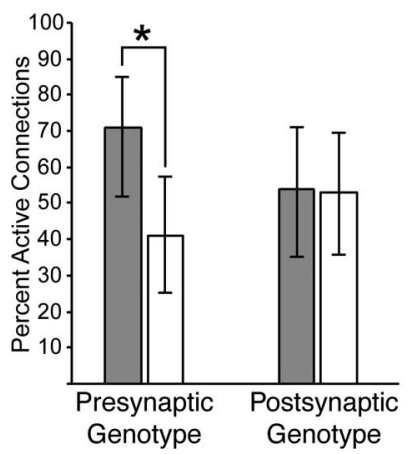

B

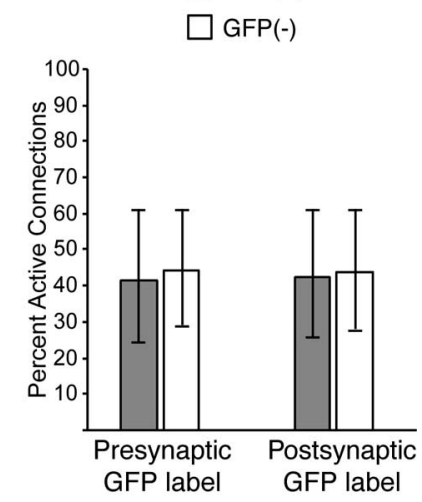

Figure 4. Functional connection probability functions of genotype. $A$, The total proportion of neuron pairs with synaptic connections is shown as a function of either presynaptic or postsynaptic genotype for Fmr 1 mosaics. Error bars show the $95 \%$ confidence intervals of the proportions. The asterisk indicates that the raw number of functional connections was significantly reduced in neuron pairs with $F m r 1 \mathrm{KO}$ presynaptic neurons relative to pairs with Fmr 1 WT presynaptic neurons ( $p<0.05$, Pearson's $\chi^{2}$ test) (see Results and Materials and Methods). At the same time, the proportion of functional connections was not significantly affected by the postsynaptic Fmr 1 genotype. Note that because GFP neurons were selected for recordings at a much greater frequency than they occurred in the slices, the absolute connectivity rates calculated from these recordings do not necessarily reflect the overall mean connectivity of the slices. $B$, The total proportion of neuron pairs with synaptic connections is shown as a function of either presynaptic or postsynaptic GFP labeling in control mosaics (see Results) (total $n=58$ pairs). There was no difference in the percentage of functional connections in control mosaics caused by either presynaptic or postsynaptic GFP labeling status.

presynaptic connectivity is largely caused by WT presynaptic neurons out-competing the $\mathrm{KO}$ neurons in a mosaic environment. Analysis of connection proportions shows that WT neurons in mosaics are significantly more connected than in controls [17 connected, 7 unconnected (Fmr1 mosaic) vs 10 and 14 (control), respectively; $p=0.042$ ]. Together with the skewed abundance of WT versus KO neurons in the mosaic animals, this finding is consistent with the interpretation that synaptic competitiveness is dependent of Fmrl genotype in the mosaic environment. Because $\sim 10 \%$ of the neurons are WT and $\sim 90 \%$ are $\mathrm{KO}$, each of the WT presynaptic neurons should be very privileged in forming connections at the slight decrement of many $\mathrm{KO}$ neurons. Whereas the resulting increased connectivity in WT neurons in mosaic animals is large and statistically significant, the predicted decreased connectivity of $\mathrm{KO}$ neurons, which is shared by $\sim 9 \mathrm{KO}$ neurons per privileged WT neuron, is predicted to be of a small magnitude, explaining the lack of a statistically significant decrease.

\section{Discussion}

That wild-type neurons are more successful than Fmr1 KO neurons in forming functional synapses in a mosaic network demonstrates a cell autonomous, presynaptic role for Fmr1 in synaptic development. Several lines of evidence support the explanation that differential competitiveness results from direct impairments in presynaptic axonal development of Fmr1 KO neurons. (1) The Drosophila orthologs of FMRP (dFXR) and its interacting proteins play essential roles in axon growth and neuronal connectivity (Morales et al., 2002; Schenck et al., 2003; Pan et al., 2004). (2) FMRP is present in axons and growth cones of hippocampal neurons, and the regulation of axonal growth is altered in hippocampal neurons from Fmr1 KO mice (Antar et al., 2005, 2006).
(3) Alterations to presynaptic terminal staining have been observed in the hippocampi of Fmrl KO mice (Ivanco and Greenough, 2002; Mineur et al., 2002).

Potential molecular substrates for presynaptic alterations are provided by biochemical measurements that reveal abnormal regulation of proteins that play key roles in axonal development. For example, the translation of microtubule-associated protein $1 \mathrm{~B}$, a protein important for growth cone dynamics (Bouquet et al., 2004), and its Drosophila ortholog, Futsch, are negatively regulated by FMRP and dFXR, respectively (Zhang et al., 2001; Lu et al., 2004). In addition, studies in both fly and mouse models of FXS show abnormal expression of proteins involved in Rho GTPase signaling (Schenck et al., 2003; Gantois et al., 2006), a pathway that plays key roles in axonal development (Luo, 2000). Whereas the majority of studies in FXS models have focused on postsynaptic phenotypes, our findings along with the studies discussed above clearly identify presynaptic alterations. While it is possible that presynaptic and postsynaptic phenotypes are independent manifestations of disrupted Fmrl function, it is also possible that alterations on one side of the synapse are causative of the abnormalities on the other side of the synapse. Therefore, future work probing the cell-autonomous roles of Fmr1 using physiological and anatomical measurements in mosaic models will provide key insight into the ontogeny of FXS.

The dependence of synapse formation on presynaptic Fmr1 genotype in mouse organotypic slices suggests the possibility that a similar phenomenon occurs during synaptic development or remodeling in the brains of mosaic FXS patients. Even given overall normal numbers of neurons and synapses, if the subset of wild-type neurons form a disproportionately larger number of synapses in a mosaic network, the result could be a decrease effective neural network size, complexity, and information carrying capacity. Thus, an impairment unique to mosaic patients may come from the inability of mutant axons to out-compete wildtype axons in the making of synapses during development.

Therefore there are two distinct theoretical implications of mosaic FMRP expression. (1) Mosaic patients should have fewer neurons exhibiting previously described deficits such as aberrant synaptic plasticity compared with patients uniformly lacking FMRP, and would be predicted to have some phenotypes ameliorated compared with nonmosaic patients. This is supported by studies showing a correlation of FMRP levels with intellectual function (Reiss et al., 1995; Tassone et al., 1999). (2) Our findings predict that mosaic patients may be uniquely predisposed to phenotypes that could arise from imbalanced presynaptic connectivity. A possible example of this is provided by a previous report suggesting that autistic patients who have disrupted FMR1 function disproportionately involve mosaic FMRP expression (Reddy, 2005). That both altered functional connectivity and autistic phenotypes could result from mosaic FMR1 expression is intriguing given that abnormal functional connectivity and disrupted information carrying capacity of neural networks play central roles in theories about the neural substrates of autism (Belmonte and Bourgeron, 2006). This underscores the importance of testing for links between mosaic FMRP expression and autistic phenotypes in future studies of large cohorts of ASD and FXS patients.

\section{References}

Antar LN, Dictenberg JB, Plociniak M, Afroz R, Bassell GJ (2005) Localization of FMRP-associated mRNA granules and requirement of microtubules for activity-dependent trafficking in hippocampal neurons. Genes Brain Behav 4:350-359. 
Antar LN, Li C, Zhang H, Carroll RC, Bassell GJ (2006) Local functions for FMRP in axon growth cone motility and activity-dependent regulation of filopodia and spine synapses. Mol Cell Neurosci 32:37-48.

Bear MF, Huber KM, Warren ST (2004) The mGluR theory of fragile X mental retardation. Trends Neurosci 27:370-377.

Belmonte MK, Bourgeron T (2006) Fragile X syndrome and autism at the intersection of genetic and neural networks. Nat Neurosci 10:1221-1225.

Bouquet C, Soares S, von Boxberg Y, Ravaille-Veron M, Propst F, Nothias F (2004) Microtubule-associated protein 1B controls directionality of growth cone migration and axonal branching in regeneration of adult dorsal root ganglia neurons. J Neurosci 24:7204-7213.

Brown WT, Jenkins EC, Cohen IL, Fisch GS, Wolf-Schein EG, Gross A, Waterhouse L, Fein D, Mason-Brothers A, Ritvo E, Ruttenberg BA, Bentley W, Castells S, Opitz JM, Reynolds JF (1986) Fragile X and autism: a multicenter survey. Am J Med Genet 23:341-352.

Crawford DC, Acuña JM, Sherman SL (2001) FMR1 and the fragile X syndrome: human genome epidemiology review. Genet Med 3:359-371.

Gantois I, Vandesompele J, Speleman F, Reyniers E, D'Hooge R, Severijnen LA, Willemsen R, Tassone F, Kooy RF (2006) Expression profiling suggests underexpression of the $\mathrm{GABA}(\mathrm{A})$ receptor subunit delta in the fragile X knockout mouse model. Neurobiol Dis 21:346-357.

Godfraind JM, Reyniers E, De Boulle K, D’Hooge R, De Deyn PP, Bakker CE, Oostra BA, Kooy RF, Willems PJ (1996) Long-term potentiation in the hippocampus of fragile X knockout mice. Am J Med Genet 64:246-251.

Hadjantonakis AK, Gertsenstein M, Ikawa M, Okabe M, Nagy A (1998) Non-invasive sexing of preimplantation stage mammalian embryos. Nat Genet 19:220-222.

Hagerman RJ (2002) Physical and behavioral phenotype. In: Fragile X syndrome: diagnosis, treatment and research (Hagerman RJ, Hagerman PJ, eds), pp 3-109. Baltimore: Johns Hopkins UP.

Hagerman RJ, Ono MY, Hagerman PJ (2005) Recent advances in fragile X: a model for autism and neurodegeneration. Curr Opin Psychiatry 18:490-496.

Hanson JE, Blank M, Valenzuela RA, Garner CC, Madison DV (2007) The functional nature of synaptic circuitry is altered in area CA3 of the hippocampus in a mouse model of down syndrome. J Physiol (Lond) 579:53-67.

Huber KM, Gallagher SM, Warren ST, Bear MF (2002) Altered synaptic plasticity in a mouse model of fragile X mental retardation. Proc Natl Acad Sci USA 99:7746-7750.

Ivanco TL, Greenough WT (2002) Altered mossy fiber distributions in adult Fmr1 (FVB) knockout mice. Hippocampus 12:47-54.

Koekkoek SK, Yamaguchi K, Milojkovic BA, Dortland BR, Ruigrok TJ, Maex R, De Graaf W, Smit AE, VanderWerf F, Bakker CE, Willemsen R, Ikeda T, Kakizawa S, Onodera K, Nelson DL, Mientjes E, Joosten M, De Schutter E, Oostra BA, Ito M, et al. (2005) Deletion of FMR1 in Purkinje cells enhances parallel fiber LTD, enlarges spines, and attenuates cerebellar eyelid conditioning in fragile X syndrome. Neuron 47:339-352.

Kooy RF (2003) Of mice and the fragile X syndrome. Trends Genet 19:148-154.

Larson J, Jessen RE, Kim D, Fine AK, du Hoffmann J (2005) Age-dependent and selective impairment of long-term potentiation in the anterior piriform cortex of mice lacking the fragile $\mathrm{X}$ mental retardation protein. J Neurosci 25:9460-9469.

Li J, Pelletier MR, Perez Velazquez JL, Carlen PL (2002) Reduced cortical synaptic plasticity and GluR1 expression associated with fragile X mental retardation protein deficiency. Mol Cell Neurosci 19:138-151.

Lu R, Wang H, Liang Z, Ku L, O’Donnell WT, Li W, Warren ST, Feng Y (2004) The fragile $\mathrm{X}$ protein controls microtubule-associated protein $1 \mathrm{~B}$ translation and microtubule stability in brain neuron development. Proc Natl Acad Sci USA 101:15201-15206.

Luo L (2000) Rho GTPases in neuronal morphogenesis. Nat Rev Neurosci 1:173-180.

Martínez R, Bonilla-Henao V, Jiménez A, Lucas M, Vega C, Ramos I, Sobrino F, Pintado E (2005) Skewed X inactivation of the normal allele in fully mutated female carriers determines the levels of FMRP in blood and the fragile X phenotype. Mol Diagn 9:157-162.

Mineur YS, Sluyter F, de Wit S, Oostra BA, Crusio WE (2002) Behavioral and neuroanatomical characterization of the Fmrl knockout mouse. Hippocampus 12:39-46.

Morales J, Hiesinger PR, Schroeder AJ, Kume K, Verstreken P, Jackson FR, Nelson DL, Hassan BA (2002) Drosophila fragile X protein, DFXR, regulates neuronal morphology and function in the brain. Neuron 34:961-972.

Musumeci SA, Hagerman RJ, Ferri R, Bosco P, Dalla Bernardina B, Tassinari CA, De Sarro GB, Elia M (1999) Epilepsy and EEG findings in males with fragile X syndrome. Epilepsia 40:1092-1099.

Nolin SL, Glicksman A, Houck Jr GE, Brown WT, Dobkin CS (1994) Mosaicism in fragile X affected males. Am J Med Genet 51:509-512.

Pan L, Zhang YQ, Woodruff E, Broadie K (2004) The Drosophila fragile X gene negatively regulates neuronal elaboration and synaptic differentiation. Curr Biol 14:1863-1870.

Pieretti M, Zhang FP, Fu YH, Warren ST, Oostra BA, Caskey CT, Nelson DL (1991) Absence of expression of the FMR-1 gene in fragile X syndrome. Cell 66:817-822.

Reddy KS (2005) Cytogenetic abnormalities and fragile-X syndrome in autism spectrum disorder. BMC Med Genet 6:3.

Reiss AL, Freund LS, Baumgardner TL, Abrams MT, Denckla MB (1995) Contribution of the FMR1 gene mutation to human intellectual dysfunction. Nat Genet 11:331-334.

Rogers SJ, Wehner DE, Hagerman R (2001) The behavioral phenotype in fragile X: symptoms of autism in very young children with fragile X syndrome, idiopathic autism, and other developmental disorders. J Dev Behav Pediatr 22:409-417.

Rousseau F, Heitz D, Tarleton J, MacPherson J, Malmgren H, Dahl N, Barnicoat A, Mathew C, Mornet E, Tejada I, et al (1994) A multicenter study on genotype-phenotype correlations in the fragile $\mathrm{X}$ syndrome, using direct diagnosis with probe StB12.3: the first 2,253 cases. Am J Hum Genet 55:225-237.

Schenck A, Bardoni B, Langmann C, Harden N, Mandel JL, Giangrande A (2003) CYFIP/Sra-1 controls neuronal connectivity in Drosophila and links the Racl GTPase pathway to the fragile $\mathrm{X}$ protein. Neuron 38:887-898.

Simmler MC, Cattanach BM, Rasberry C, Rougeulle C, Avner P (1993) Mapping the murine Xce locus with (CA)n repeats. Mamm Genome 4:523-530.

Tassone F, Hagerman RJ, Iklé DN, Dyer PN, Lampe M, Willemsen R, Oostra BA, Taylor AK (1999) FMRP expression as a potential prognostic indicator in fragile X syndrome. Am J Med Genet 84:250-261.

The Dutch-Belgian Fragile X Consortium (1994) Fmrl knockout mice: a model to study fragile X mental retardation. Cell 78:23-33.

Zhang YQ, Bailey AM, Matthies HJ, Renden RB, Smith MA, Speese SD, Rubin GM, Broadie K (2001) Drosophila fragile X-related gene regulates the MAP1B homolog Futsch to control synaptic structure and function. Cell 107:591-603.

Zhao MG, Toyoda H, Ko SW, Ding HK, Wu LJ, Zhuo M (2005) Deficits in trace fear memory and long-term potentiation in a mouse model for fragile X syndrome. J Neurosci 25:7385-7392. 